\title{
HYDROXYAPATITE COATING ON CARBON COMPOSITE HIP IMPLANTS IN DOGS
}

\author{
G. L. MAISTRELLI, N. MAHOMED, D. GARBUZ, V. FORNASIER, I. J. HARRINGTON, A. BINNINGTON
}

From Toronto East General and Orthopaedic Hospital and the University of Toronto

\begin{abstract}
In 33 dogs we implanted femoral stens made either of carbon composite, some coated with hydroxyapatite, or of titanium alloy with a porous coating.

Osseo-integration was greater in the hydroxyapatite-coated than in the uncoated stems $(p<0.001)$. Push-out tests, at an average of $\mathbf{7 . 2}$ months after implantation, showed a six-fold increase in interface shear strength and a twelve-fold increase in shear stiffiness in the hydroxyapatite-coated group compared with noncoated implants. The highest shear-strength values were found in the porous-coated titanium alloy stems, around which there was also the most resorptive bone remodelling.
\end{abstract}

Total hip replacements are being increasingly performed on younger and more active patients and therefore issues such as the effect of ion release (Bartolozzi and Black 1985; Black 1988), optimum load transfer to bone (Küsswetter et al 1984; Brown and Ring 1985; Engh and Bobyn 1988), fatigue performance (Stauffer 1982; Yue, Pilliar and Weatherly 1984; Hamblen and Paul 1988) and implant-bone bonding (Haddad, Cook and Thomas 1987; Collier et al 1988) are becoming more relevant. Several in vitro and in vivo studies have shown that a more physiological state can be restored in the proximal femoral bone if the modulus of elasticity of the implant material is reduced (Lewis et al 1984; Djerf and Gillquist 1987; Maistrelli et al 1991). Due to recent technological advances, carbon-fibre-reinforced composite materials now offer strength comparable to that of metals plus the ability to adapt their elastic characteristics (Harms, Mittelmeier and Mäusle 1984; Skinner 1988). Composite prostheses with greater strength and more flexibility than

G. L. Maistrelli, MD, FRCS C, Assistant Professor N. Mahomed, MD, Research Fellow

D. Garbuz, MD, Research Fellow

I. J. Harrington, MD, FRCS C, Assistant Professor

Department of Orthopaedic Surgery, Toronto East General and Orthopaedic Hospital, 825 Coxwell Avenue, Toronto, Ontario, Canada M4C 3E7.

V. Fornasier, MD, FRCP C, Senior Staff Pathologist

Princess Margaret Hospital, 500 Sherbourne Street, Toronto, Ontario, Canada M4X 1K9.

A. Binnington, DVM, MSc, ACVS, Associate Professor

University of Guelph Veterinary College, Guelph, Ontario, Canada N1G 2W1.

Correspondence should be sent to Dr G. L. Maistrelli.

(C) 1992 British Editorial Society of Bone and Joint Surgery

$0301-620 \mathrm{X} / 92 / 3355 \$ 2.00$

J Bone Joint Surg [Br] 1992; 74-B: 452-6. metal ones can be produced. Nevertheless the reduction of the elastic modulus is not the sole answer to the problems of hip implantation. There is now clear evidence that most of the cementless prostheses currently in use fail to achieve direct anchorage with surrounding bone and depend for fixation upon the ingrowth of fibrous tissue (Ryd 1986; Haddad et al 1987; Collier et al 1988).

Recent investigations suggest that a 'chemical bond' may form between bone and calcium-phosphate coatings such as hydroxyapatite (HA), when they are applied to the surfaces of implants (Cook and Thomas 1988; Geesink, de Groot and Klein 1988; Lemons 1988; Søballe et al 1990). Most of the animal studies on HA bonding, however, have been on unloaded implants or have lacked quantitative measurements. Our aim was to compare quantitatively, in a loaded canine hip model, the interface of carbon composite stems, with and without HA coating, with that of a porous-coated titanium alloy stem. We also studied the intracortical porosity of the surrounding compact bone for evidence of stress shielding.

\section{MATERIALS AND METHODS}

Over a two-year period we implanted femoral stems into the right hips of 33 adult mongrel dogs weighing between 26 and $32 \mathrm{~kg}$. In phase one, the histological study, 14 textured carbon composite (TCF) stems (Osteo, Selzach, Switzerland) were implanted; seven were coated with HA. Phase two was a mechanical study using 19 implanted stems; seven HA-coated TCF, six non-coated TCF and six porous-coated Ti-6Al-4V. All implants were of similar size and geometry (Fig. 1).

The TCF stems had a core of endless carbon fibre impregnated with a thermoset polymer based on triazin resin. The core was encased in an outer layer of pure 


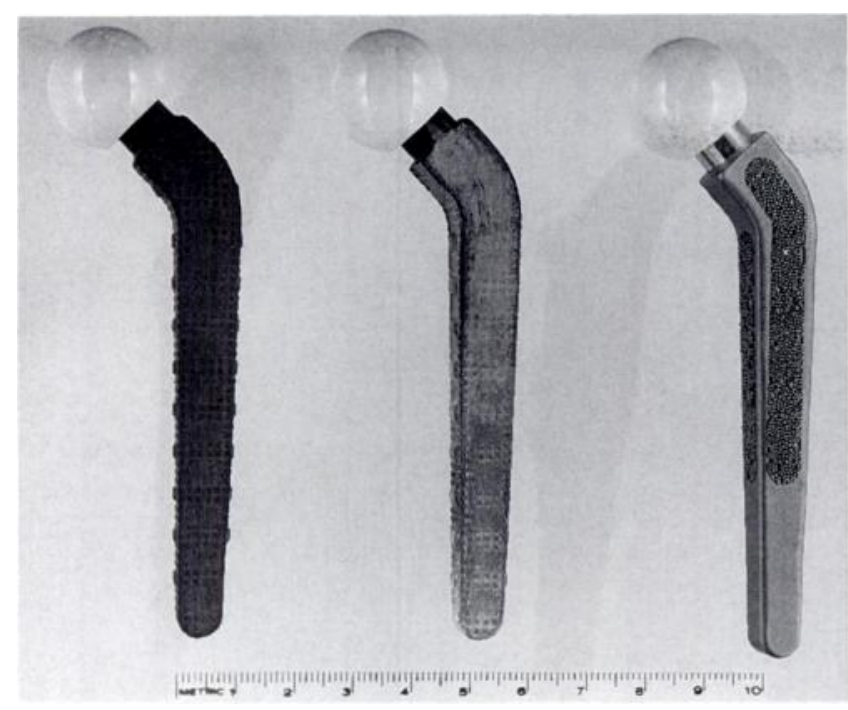

Fig. 1

Canine total hip implants. Left to right: non-coated TCF stem, HAcoated TCF stem, porous-coated titanium stem.

triazin resin. Half were coated with a calcium-phosphate layer using a low-temperature, dip-coating technique (Ro. Bosch GmbH, Stuttgart, Germany). This dense and relatively smooth layer was composed of $90 \%$ HA $(\mathrm{Ca} / \mathrm{P}=1.67)$ and $10 \% \mathrm{TCP}$ (tricalcium phosphate) and was approximately $150 \mu \mathrm{m}$ thick. The metal implants were solid $\mathrm{Ti}-6 \mathrm{Al}-4 \mathrm{~V}$ to which titanium beads had been sintered over the proximal half of the stem in a single layer, to provide a mean pore size of $150 \mu \mathrm{m}$.

An anterolateral approach was used in all cases. Antibiotics were begun pre-operatively and continued for 48 hours postoperatively. The animals were allowed unrestricted weight-bearing and walked daily during the whole period of the study. We performed force-plate analysis before surgery and before they were killed; the animals were walked along a runway containing two force platforms (Advanced Medical Technology Incorporated, Newton, Massachusetts).

Phase one: histological study. The 14 animals were killed at an average of 6.4 months ( 2 to 8 ) after implantation and contact radiographs were made of the resected specimens.

Each specimen was fixed in formaldehyde for at least 48 hours and then placed in graduated concentrations of alcohol. Progressive concentrations of Spurr's low-viscosity medium were used for embedding. Sections, about $1 \mathrm{~mm}$ thick, were cut 1,4 and $6 \mathrm{~cm}$ above the tip of the prosthesis and mounted on a plastic support with cyanoacrylate glue. The exposed surface was ground and polished with 4000 grit paper, etched, and then stained with toluidine blue (Schenk, Olah and Herrmann 1984).

The proportion of bone apposition along the interface between the implant and the surrounding tissue was measured, the porosity of the femoral cortex at each level quantified to estimate the degree of stress shielding, and the character of the tissue immediately surrounding the prosthesis assessed.

Bone deposition around the implant was expressed as a percentage of the total surface area of the boneimplant interface, quantified by a Zeiss Video Plan Image Analyser. Femoral cortical porosity was expressed as that percentage of the total cortical area occupied by canals, and indicated the net result of the remodelling process. These measurements were undertaken with the Leco 2001 Image Analyser (Leco, St Joseph, Michigan). Each test femur was compared with its contralateral control.

The data were analysed for statistical significance using Student's $t$-test.

Phase two: biomechanical study. The 19 animals comprising the test and control groups were killed at an average of 7.2 months ( 4 to 8 ) after implantation. Their femora were kept in saline at a controlled temperature and, on the same day, underwent mechanical testing to determine micromotion, shear strength and stiffness at the interface.

Before testing, three holes were drilled through the medial cortex at fixed levels from the lesser trochanter. The distal femur was potted and mounted into the load train of the Materials Testing Machine (MTS Model 858, Biomix, Minneapolis, Minnesota). A linear variable differential transformer (LVDT) was fixed to the medial aspect of the proximal femur and the spring-loaded measuring probe inserted through the proximal drill hole so that its tip rested on the implant stem but was not in contact with the cortical bone. It therefore recorded stem movement relative to the femur. The femur was cyclically loaded at $100 \mathrm{~N}, 150 \mathrm{~N}, 200 \mathrm{~N}, 250 \mathrm{~N}$ and $300 \mathrm{~N}$. The force-displacement measurements were digitised by a Data Translation DT 2801 A A/D converter (Transduction, Mississauga, Ontario, Canada) and recorded on microcomputer diskette. The entire procedure was then repeated for each of the other two drill holes.

Immediately after the micromotion tests, transverse sections, $8 \mathrm{~mm}$ thick, were cut at three levels across the proximal part of the stem. Each specimen was positioned within the load train of the MTS for push-out tests. Normal force was applied to the surface to produce a shearing load between the implant and the bone. The servohydraulic actuator displaced the section at a rate of $2.08 \mathrm{~mm} / \mathrm{sec}$. Load-displacement curves were used to determine the ultimate shear strength. These data were normalised against the interface area for each specimen to facilitate uniform comparison. The maximum force attained during each trial was defined as the push-out strength.

\section{RESULTS}

Force-plate analysis. Force-plate analysis immediately before killing confirmed that all the dogs walked with adequate weight-bearing on the operated limb. The peak vertical force on the implanted limb was more than $90 \%$ 
of the non-operated (control) limb in all animals. In the HA-coated TCF group it was $98 \%$, in the non-coated TCF group $94.1 \%$, and in the Ti-6Al-4V group $95.8 \%$. The differences are not statistically significant.

Radiographic analysis. None of the TCF specimens showed evidence of proximal bone resorption. Remodelling changes were seen both proximally and distally in three titanium-implanted femurs (Fig. 2) and a radiolucent line was invariably present around the non-porous distal portion of the titanium stems.

An interesting feature of all the HA-coated TCF stems was an increase in the trabecular bone density in the metaphyseal region (Fig. 3a). This extended from the endosteal surface of the cortex to the surface of the prosthesis (Fig. 3b). No radiolucent areas were noted adjacent to the HA coating.

Histology. In both the TCF implant groups there was increased density of the trabecular bone proximally. In the HA-coated implants bone was in direct contact with the coating on the surface of the prosthesis indicating good osseo-integration (Fig. 4).

The morphometric analysis showed osseo-integration over an average of $29 \%$ of the HA-coated TCF stems and over $8.8 \%$ of the non-coated TCF stems ( $p=0.001)$. Proximally, the HA-coated TCF stems had osseointegration of $41.9 \%$ while the non-coated stems showed only $5.9 \%(\mathrm{p}<0.001)$. The titanium implants showed direct bone bonding on only $5.8 \%$ of the porous surface with no bony apposition in the distal smooth sections of the implants.

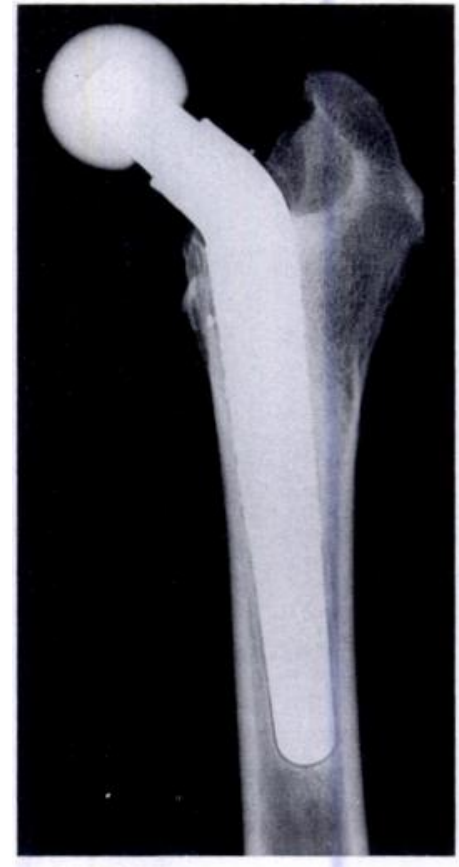

Fig. 2a

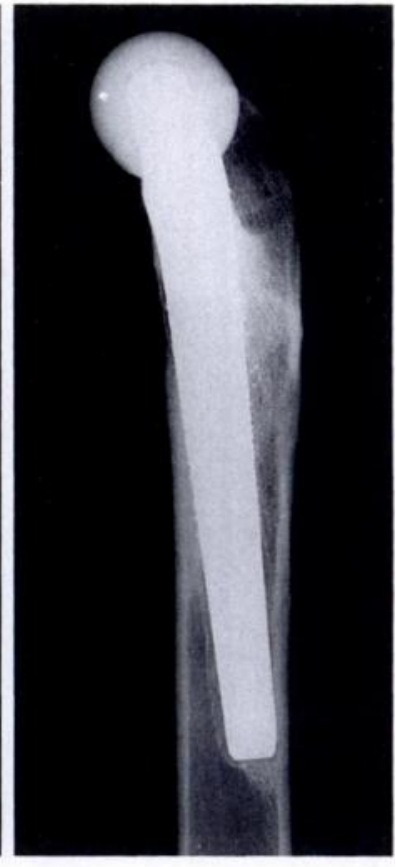

Fig. 2b

Post-mortem contact radiographs of a titanium porous-coated stem with evidence of proximal and distal remodelling and a radiolucent line surrounding the distal smooth portion.

There was more bone porosity $(4.1 \%)$ around the titanium implants $(\mathrm{p}<0.05)$; the overall femoral bone porosity around the HA-coated TCF stems was $1.93 \%$ and around the non-coated TCF stems $2.25 \%$. This latter
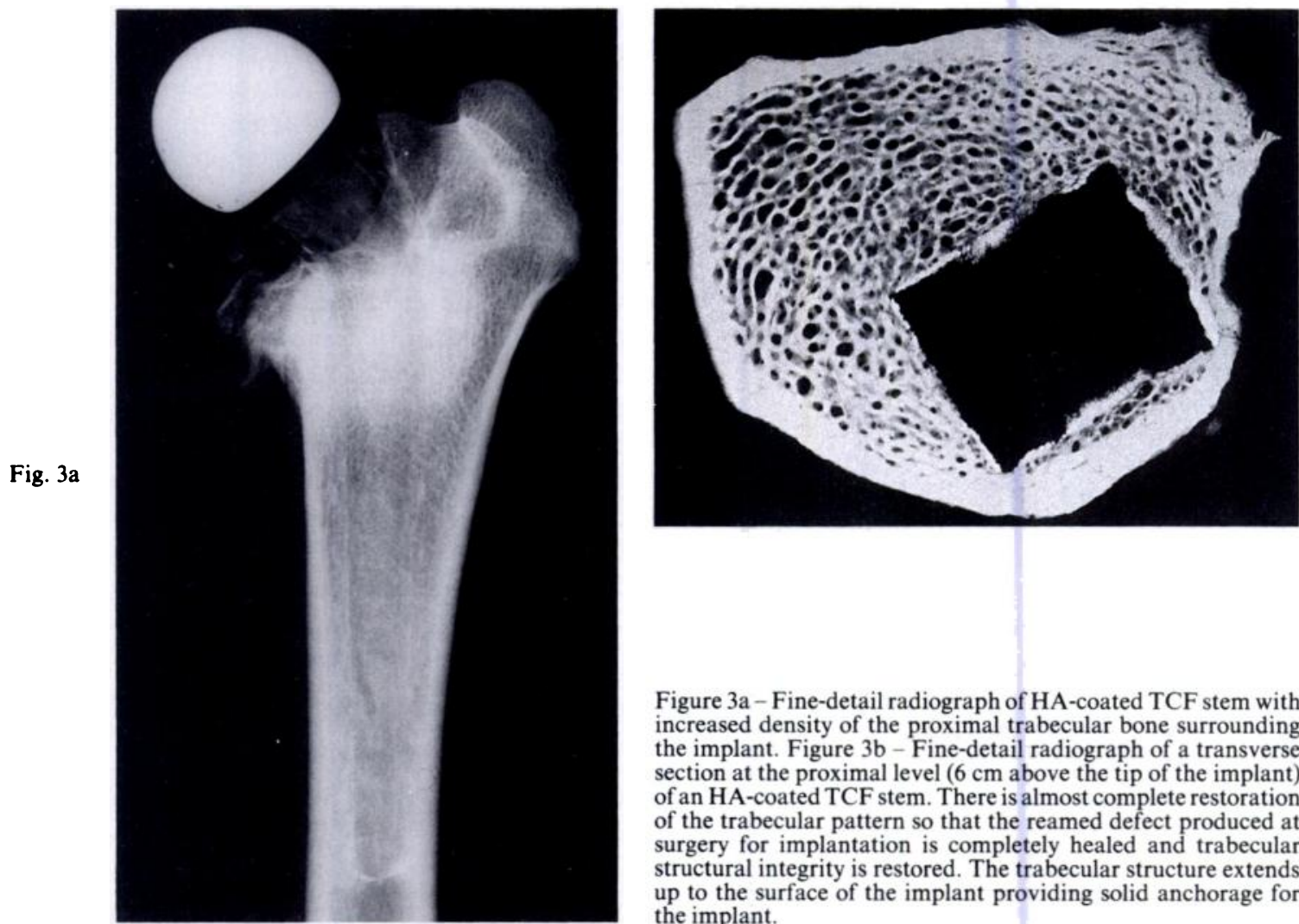

Fig. 3b

Figure 3a-Fine-detail radiograph of HA-coated TCF stem with increased density of the proximal trabecular bone surrounding the implant. Figure $3 \mathrm{~b}-$ Fine-detail radiograph of a transverse section at the proximal level $(6 \mathrm{~cm}$ above the tip of the implant) of an HA-coated TCF stem. There is almost complete restoration of the trabecular pattern so that the reamed defect produced at surgery for implantation is completely healed and trabecular structural integrity is restored. The trabecular structure extends up to the surface of the implant providing solid anchorage for the implant. 


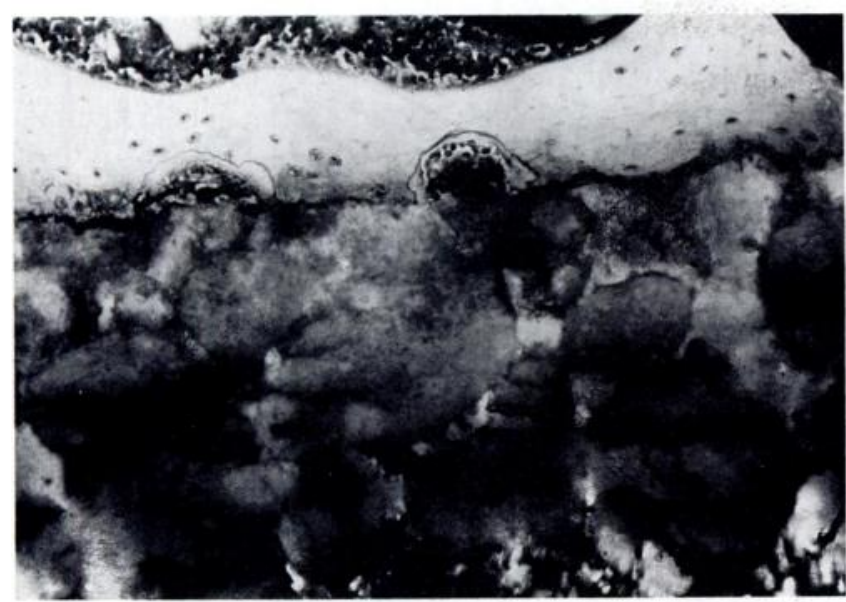

Fig. 4

Bone abutting directly onto the HA coating with no intervening connective tissue $(\times 125)$.

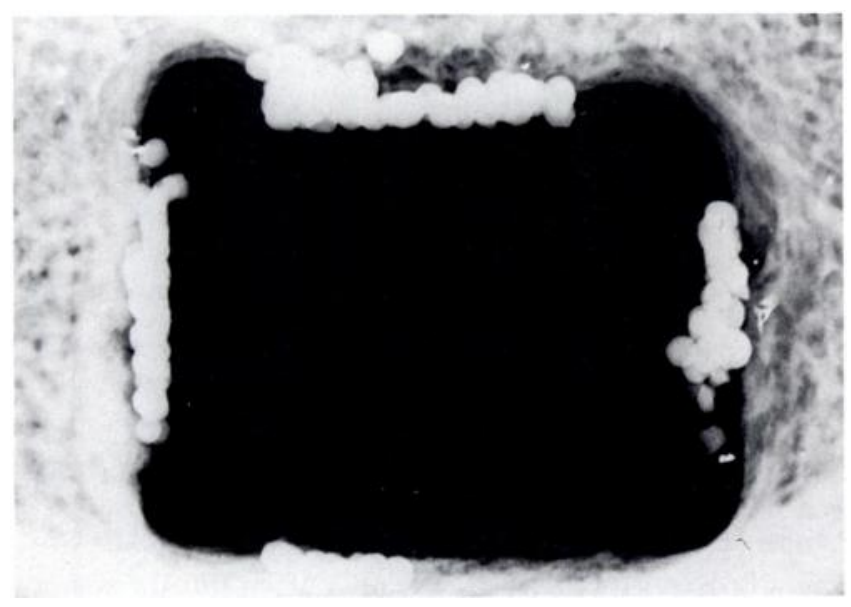

Fig. 5

Loose beads embedded in fibrous tissue after push-out testing.

Table I. Micromotion of the implanted stem at three sites below the lesser trochanter

\begin{tabular}{lllll}
\hline \multirow{3}{*}{ Stem type } & \multicolumn{4}{l}{ Micromotion $(\mu \mathrm{m})$} \\
\cline { 2 - 5 } & Proximal & Middle & Distal & Mean \\
\hline Non-coated TFC & 17.5 & 17.5 & 12.5 & 15.8 \\
HA-coated TFC & 10.0 & 10.0 & 10.0 & 10.0 \\
Titanium & 18.3 & 11.7 & 11.7 & 13.9 \\
\hline
\end{tabular}

Table II. Mean shear strength to push-out of the implanted stem at three sites below the lesser trochanter

\begin{tabular}{|c|c|c|c|c|c|}
\hline \multirow[b]{2}{*}{ Stem type } & \multicolumn{4}{|c|}{ Mean shear strength (MPa) } & \multirow{2}{*}{$\begin{array}{l}\text { p value } \\
\text { compared } \\
\text { with other } \\
2 \text { groups }\end{array}$} \\
\hline & Proximal & Middle & Distal & Mean & \\
\hline Non-coated TFC & 0.14 & 0.17 & 0.78 & 0.32 & $<0.001$ \\
\hline HA-coated TFC & 2.72 & 1.84 & 1.43 & 2.03 & $<0.001$ \\
\hline Titanium & 3.29 & 3.52 & 3.80 & 3.54 & $<0.003$ \\
\hline
\end{tabular}

difference is not statistically significant. There was no inflammatory reaction at the interfaces in any group.

Mechanical analysis. The micromotion of the three types of implant was different (Table I); the HA-coated TCF stems moved only a mean $10 \mu \mathrm{m}$. Their shear strength was 6.4 times greater than the non-coated TCF implants ( $p<0.001$, Table II) whereas the mean shear strength of the porous-coated titanium implants was greatest at 3.54 $\mathrm{MPa}(\mathrm{p}<0.003)$. In the HA-coated group shear strength was greatest proximally and progressively decreased distally; the other two groups had the opposite trend. The mean interface stiffness was significantly higher in the HA-coated group than in the non-coated group, while the highest values were found in the titanium-implant group (Table III). Failure occurred predominantly at the bone-implant interface in the TCF stems, but small amounts of bone adhered to the HA-coated implants after push-out. In only one of the $21 \mathrm{HA}$-coated sections was there failure at the HA coating-substrate interface. Nine of the titanium sections, however, failed between the porous-coating and its base (Fig. 5), most of the loose beads being embedded in fibrous tissue only.

\section{DISCUSSION}

Several of our conclusions may be of clinical significance for the long-term survival of hip implants. Our radiographic and morphometric data suggest that composite low-modulus stems have a beneficial effect on adaptive remodelling changes in the surrounding bone. The better bone bonding observed in the HA-coated stems did not result in any increase in the stress-shielding effect.

Our study also indicates that direct bone anchorage can occur with HA-coated TCF prostheses under the in vivo condition of cyclical loading. We think that this is the first study in which direct bone bonding in these circumstances has been quantitatively analysed. Bone apposition and trabecular bone formation were greatest proximally and we regard this as an important factor in the prevention of cantilever and torsional loading with their potential for failure. This conclusion is supported by the absence of any increase in cortical porosity, indicating that stress shielding did not occur. The very small micromotion found in all three study groups confirmed the excellent stability of all the implanted stems. The least micromotion was found in the HA-coated stems.

The results of the push-out tests showed that the HA-

Table III. Interface stiffness of the implanted stem at three sites below the lesser trochanter

\begin{tabular}{lcrrr}
\hline & \multicolumn{4}{c}{ Interface stifiness (N/mm) } \\
\cline { 2 - 5 } Stem type & Proximal & Middle & Distal & Mean \\
\hline Non-coated TFC & 98 & 100 & 464 & 220 \\
HA-coated TFC & 3182 & 2886 & 1880 & 2649 \\
Titanium & 3711 & 4595 & 4885 & 4397 \\
\hline
\end{tabular}


coated implants engaged a sixfold increase in interface shear strength and a twelvefold increase in shear stiffness compared with the non-coated TCF group. The low shearstiffness values in the non-coated samples were consistent with the interposition of fibrous tissue at their interfaces. We deduce that the interface shear strength and stiffness values of the 'press-fit' type of hip prostheses in clinical use today must be quite negligible. This observation, taken with the slightly higher micromotion detected in the uncoated stems, raises some doubts about the longterm performance of 'press-fit' implants, either metal or composite.

Evidence of failure at the implant-HA coating interface was detected in only one of 21 sections tested by push-out. The highest shear-strength values were obtained in the titanium group, no doubt because the large surface area of the porous coating increases the contact area with bone and fibrous tissue and provides mechanical fixation of the implant. It is therefore possible that the strength of the interface between the stem and its porous coat is similar or even less than that of the HA coat and the TCF stem. In $50 \%$ of the porous-coated stems there was push- out failure at the bead-substrate level which raises further doubts about the long-term integrity of such surfaces (Buchert et al 1986; Cheng and Gross 1988). Contact radiographs and light-microscope analysis of the porous interface in both intact and failed beads showed evidence of inconsistent bone ingrowth and very little direct bone bonding.

The disadvantages of this form of fixation are numerous if one takes into account the increased risks of surface corrosion, notch sensitivity and toxic metal ion release as well as the potential for increased femoral bone resorption. Alternative materials and modes of fixation should continue to be investigated and the contribution of a composite low-modulus stem with a stable osteoconductive calcium-phosphate coating could well be a solution to these current problems.

We wish to acknowledge financial support from the Toronto East General Hospital Research Foundation and the Rea Foundation. We also acknowledge the invaluable contribution of Trevor Hearn, $\mathrm{PhD}$, to the biomechanical testing.

No benefits in any form have been received or will be received from a commercial party related directly or indirectly to the subject of this article.

\section{REFERENCES}

Bartolozzi A, Black J. Chromium concentrations in serum, blood clot and urine from patients following total hip arthroplasty. Biomaterials $1985 ; 6: 2-8$

Black J. Editorial : Does corrosion matter? J Bone Joint Surg [Br] 1988; 70-B:517-20

Brown IW, Ring PA. Osteolytic changes in the upper femoral shaft following porous-coated hip replacement. J Bone Joint Surg [Br] $1985 ; 67-B: 218-21$.

Buchert PK, Vaughn BK, Mallory TH, Engh CA, Bobyn JD. Excessive metal release due to loosening and fretting of sintered particles on porous-coated hip prostheses: report of two cases. J Bone Joint Surg [Am] 1986; 68-A :606-9.

Cheng CL, Gross AE. Loosening of the porous coating in total knee replacement. J Bone Joint Surg [Br] 1988; 70-B:377-81.

Collier JP, Mayor MB, Chae JC, et al. Macroscopic and microscopic evidence of prosthetic-fixation with porous-coated materials. Clin Orthop 1988; $235: 173-80$.

Cook SD, Thomas KA. Hydroxyapatite-coated porous titanium for use as an orthopedic biologic attachment system. Clin Orthop 1988; 230:303-12.

Djerf K, Gillquist J. Calcar unloading after hip replacement. Acta Orthop Scand $1987 ; 58: 97-103$.

Engh CA, Bobyn JD. The influence of stem size and extent of porous coating on femoral bone resorption after primary cementless hip arthroplasty. Clin Orthop 1988; $231: 7-28$.

Geesink RGT, de Groot K, Klein CPAT. Bonding of bone to apatitecoated implants. J Bone Joint Surg [Br] 1988; 70-B:17-22.

Haddad RJ, Cook SD, Thomas KA. Biological fixation of porous-coated implants. J Bone Joint Surg [Am] 1987; 69-A:1459-66.

Hamblen DL, Paul JP. The integrity of porous coatings for cementless implants. J Bone Joint Surg [Br] 1988; 70-B:521-3.
Harms J, Mittelmeier H, Mäusle E. Results of animal studies on the use of carbon fiber-reinforced plastic prostheses. In: Morscher E, ed. The cementless fixation of hip endoprostheses. Berlin: SpringerVerlag, 1984:249-51.

Küsswetter H, Gabriel E, Stuhler T, Töpfer L. Remodeling of the femur in conventionally-implanted hip prostheses. In: Morscher E, ed. The cementless fixation of hip endoprostheses. Berlin: SpringerVerlag, 1984:17-20.

Lemons JE. Hydroxyapatite coatings. Clin Orthop 1988; 235 :220-3.

Lewis JL, Askew MJ, Wixson RL, Kramer GM, Tarr RR. The influence of prosthetic stem stiffness and of a calcar collar on stresses in the proximal end of the femur with a cemented femoral component. J Bone Joint Surg [ Am] 1984; 66-A :280-6.

Maistrelli GL, Fornasier V, Binnington A, et al. The effect of stem modulus in a total hip arthroplasty model. J Bone Joint Surg [Br] $1991 ; 73-B: 43-6$.

Ryd L. Micromotion in knee arthroplasty : a roentgen stereophotogrammetric analysis of tibial component fixation. Acta Orthop Scand 1986; 57 :Suppl 220.

Schenk RK, Olah AJ, Herrmann W. Preparation of calcified tissues for light microscopy. In: Dickson GR, ed. Methods of calcified tissue preparation. Amsterdam : Elsevier, 1984:1-56.

Skinner HB. Composite technology for total hip arthroplasty. Clin Orthop 1988; $235: 224-36$.

Soballe K, Hansen ES, Brockstedt-Rasmussen H, Pedersen CM, Bünger C. Hydroxyapatite coating enhances fixation of porous coated implants. Acta Orthop Scand 1990; 61 :299-306.

Stauffer RN. Ten-year follow-up study of total hip replacement. J Bone Joint Surg [Am] 1982; 64-A :983-90.

YueS, Pilliar RM, Weatherly GC. The fatigue strength of porous-coated Ti-6\%Al-4\% $\mathrm{V}$ implant alloy. J Biomed Mater Res $1984 ; 18: 1043$ 58. 